\title{
The Reform and Innovation on Bilingual Teaching of Business Administration Discipline in Chinese Universities
}

\author{
Wang Lina \\ School of Business Management, Shanghai Lixin University of Commerce, Shanghai (fdwanglina@ 126.com)
}

\begin{abstract}
In order to meet the development of economic globalization, the colleges of business administration have launched a bilingual teaching method in most universities. Bilingual education is good for shaping an international compound talent, however, due to the lack of qualified teachers, simplification of teaching methods, similarity of the curriculum, the effect of bilingual teaching is not as good as expected. Therefore, the bilingual teaching of business administration must make be reformed and innovated appropriately. Such as, introducing the foreign materials, lesson plans, learning curriculum system and teaching methods. Diversify the teaching methods, for example, introducing participating in teaching method, experiences teaching method and scenario simulation teaching method etc.
\end{abstract}

Keywords — business administration, bilingual teaching, globalization, participating in teaching

\section{我国高校工商管理专业双语教学模式的改革与创新}

王丽娜

上海立信会计学院工商管理学院, 上海, 中国

摘 要 为了适应经济全球化的发展趋势, 我国高校工商管理专业普遍开展了双语教学的授课方式。双语教学有利于培养国际化 复合型人才, 但由于师资力量不足、教学组织形式单一、课程设置趋同等因素制约了双语教学的效果。因此, 我国高校工商管理专业 双语教学必须进行相应的改革和创新, 即在引入国外教材和教案的同时, 积极借鉴国外的课程设置体系和教学方法, 如参与式教学、 体验式教学和情景模拟教学等等。

关键词 工商管理专业, 双语教学, 国际化, 参与式教学

\section{1. 引言}

随着经济全球化发展和我国对外开放的不断深化, 人 才市场的需求也在向国际化、应用型和创新型的方向发展。 高等院校人才培养的目标和战略必须尽快迎合经济发展和 人才需求的变化, 培养国际化程度高、适应能力强、具有 创新性思维的复合型人才。因而, 国内许多高校的工商管 理专业都相继开展了双语教学、国际化方向班等系列教学 模式的创新。双语教学有助于学生提高英语的语言表达能 力, 掌握专业知识的英文表述, 使学生在毕业之后迅速适 应跨国公司或国际化的工作环境。同时, 双语教学也有利 于国内高校学习国外先进教学模式, 实现与国外高等教育 接轨。无论从高等教育国际化的视角, 还是从人才市场需
求变化的角度, 工商管理专业开展双语教学都就有重要的 现实意义。但是, 工商管理专业双语教学模式在开展过程 中也遇到了一些问题和困难, 如学生抱怨不适应, 教师师 资力量薄弱, 课程体系设置不合理等等直接影响了双语教 学的效果, 进而导致学生的学习效果下降。由此可见, 必 须根据中国的国情, 充分借鉴国外的教学模式和先进经验 对我国高校工商管理专业的双语教学进行改革和创新。

\section{2. 提高双语教学的教学条件}

工商管理专业双语教学的效果是培养国际化应用型人 才的关键。目前, 虽然国内大多数高校工商管理专业都开 设了双语课程, 但由于教学条件和相关设施的限制, 以及 
学生英语水平参差不齐等原因, 英语双语教学流于形式, 即仅仅选择了英文的教材, 实际上并没有达到应有的效果。 为了提高双语教学的效果, 其重要的前提条件就是提高双 语教学的教学条件。

\section{1 通过过渡性教学和激励措施提高学生的适应能力}

开展双语教学并不是简单地将中文讲授的课程改为英 文讲授, 同时还需要学生的积极配合, 才能达到应有的效 果。工商管理专业不同于英语专业, 如果没有学生进行篎 选和训练, 就不能确保学生有能力接受双语教学。而且, 英语能力欠缺的学生对双语教学具有排斥心理, 同样的学 分, 学生宁愿选择中文课程, 或者, 要求教授在课堂上多 讲中文。另外, 由于双语教学要求学生花更多的课下时间 来预习和复习, 才能保证教学质量, 而学生认为这显然增 加了他们的学习负担。因此, 在进行双语教学之前, 学校 应该组织对学生进行选拔和英语的培训, 使学生尽快适应 双语教学方式。

\section{2 加强双语教学的师资力量}

双语教学的师资力量直接决定了双语教学的效果。目 前, 许多高校在师资力量不足的情况下, 仓促开展双语教 学。由于教师和学生都没有充分的准备, 双语教学没有达 到预计的效果。首先, 校方应该尽量创造条件组织开设双 语课的教师参加母语为英语国家的进修深造。也可以组织 教师参加国内的短期培训。教师在进修过程中, 通过旁听 和选修相关课程, 不仅可以提高语言能力, 还可以学习国 外的课堂教学方法, 从而提高课堂教学效果。其次, 校方 还可以积极引进国外大学的教师, 或邀请国外教师利用假 期来中国短期执教, 国内教师进行相应地辅助教学。双方 教师在合作的过程也有利于中方教师双语教学水平的提 高。最后, 建立合理的激励机制, 鼓励教师投入到双语教 学中。由于教师承担双语教学需要花费更多的时间和精力 来准备, 适当的激励可以鼓励教师积极有效地提高教学质 量。

\section{3 通过与国外高校合作办学提高教学效果}

高校可以通过积极开展中外合作办学, 争取更多的资 源和机会, 促进教师和学生重视双语教学, 进而提高教学 效果。利用中外合作办学, 学生和教师都能够获得短期交 流和进修的机会。而且, 大部分学生短期交流之后, 开阔 了视野, 获取了国外的信息, 进而选择毕业后出国深造, 这些极大地促进了学生对于双语课的学习积极性。中外合 作办学的模式有多种: 不仅包括学历教育, 也包括以技能
和证书培训为主的非学历教育; 双校园和单校园; 全日制 和非全日制; 但文凭和双文凭等等。不同形式的中外合作 办学都必然要求双语教学的配合, 同时, 也促进学生对双 语教学的重视, 以及教师教学水平的提高。

\section{3. 构建适合中国特色的工商管理专业双语课程体系}

\section{1 公共基础课程}

公共基础课程除了管理学、经济学、专业英语等课程 之外, 根据市场环境对学生素质的要求, 侧重学生自学能 力、沟通能力、适应能力、写作能力、创新精神培养的相 关课程, 例如, 商业信函写作、商务礼仪、孙子兵法、创 新意识培养、团队合作精神、心理健康等等。这些课程对 于学生对于适应社会市场环境, 克服困难, 通过再学习积 累工作经验具有较大的帮助。

\section{2 公共基础课程}

根据不同的培养方向, 专业必修课可以设置能够体现 培养定位和具有特色的专业课程。例如创业方向、运营管 理方向、战略管理方向、人力资源管理方向等等。不同的 专业方向和特色要求专业课程的设置和重点也应该有所差 异, 还要根据人才需求的要求, 不断创新专业课程设置。 另外, 专业必修课在奠定理论基础的同时, 更要注重应用 性课程的开设, 有利于学生毕业后适应社会的需要。

\section{3 选修课}

选修课的开设主要体现多元化、丰富化、技能化等特 点。除了专业选修课, 鼓励学生选择跨专业选修课程, 以 丰富学生的知识领域。另外, 选修课的考核和学分认定形 式可以多样化, 不必局限在与专业相关的课程。试想如果 当年乔布斯没有旁听书法课, 也许就没有现在外观线条流 畅, 字体精美的苹果电脑。再者, 鼓励学生学研结合, 增 加参与实践的机会。学生每个学期都可以利用寒暑假参加 与专业相关的实习, 或者在学校的实习基地实习, 实习的 表现由工作单位的主管打分, 并可以抵扣学分。

\section{4 专业实验课程}

专业实验课程培养的是学生的实践能力和实际解决问 题的能力。现代社会对于大学生实际工作能力的要求越来 越高, 因此, 应用型专业课程, 如战略管理、人力资源管 理、客户关系管理等课程都应该配合建立相应的实验室, 让学生模拟实际工作环境进行操作。只有让学生认识到了 所学理论在实践中的应用空间, 才能够激发学习的动力, 促进学生积极主动地努力学习。同时, 通过学分设置鼓励 
学生参加专业资格证书的相关考试, 以此增加学生的就业 竞争力。

\section{4. 引进国外高校工商管理专业的教学方法}

工商管理专业的双语教学不仅仅是采用国外教材和课 件, 更重要的是要积极引进国外高校先进的教学方法, 例 如, 参与式教学、情境模拟教学和案例教学等等, 从而达 到预期的教学效果和人才培养的目标。

\section{1 参与式教学法让课堂活跃起来}

参与式教学法是以学生为中心, 通过教师与学生之间 的平等交流, 让学生主动地参与到课堂中来。欧美高校课 堂教学非常注重教师的启发和师生的互动。教师通过课堂 提问来启发学生思考, 从而引导学生自己找到答案并总结 规律。其中, 参与式教学要求教师根据学生的实际需要和 愿望, 设计与教学内容相关的问题引导学生回答。教师用 于课堂提问的问题大多来源于日常生活或学生的兼职经 历, 便于学生回答和思考。教学过程中, 学生通过问题的 回答和教师的提示, 逐步发现问题的本质, 并找到解决问 题的对策, 从而达到课程学习的目标。在学生参与课堂讨 论活动或自己动手设计方案的过程中, 教师仅仅起协助的 作用, 让学生成为课堂的主体。参与式的教学方法充分实 现了学生的体验式学习。学生的作为参与者成为了课堂学 习的核心, 尊重了学生的个性特征, 同时也有助于培养学 生的创新精神。从根本上克服了被动式的课堂讲授教学法 的弊端。

\section{2 情景模拟实验的体验式教学法培养学生实践能力}

情景模拟教学是通过案例或相关软件模拟真实的工作 场景, 让学生运用相关理论对现实问题进行决策。情景模 拟教学使学生参与到模拟的实践工作中去, 促进学生主动 收集信息、查找理论支持, 通过团队讨论、集体思考和头 脑风暴等方式解决问题。让学生在虚拟的工作环境中通过 体验去感知、理解、领悟、验证教学内容, 使学生在获取 知识的同时做到观念、判断、技能的自主形成并被主动掌 握。因此, 情景模拟教学法能够在很大程度上加深理论学 习的记忆, 进而提高教学效果。比如, 在介绍公司治理制 度中, 股东大会、董事会和总经理的关系时, 可以设计几 个董事会决策的场景, 如董事会如何制定总经理薪酬, 董 事会如何及时辞退和更换不合格的总经理, 然后让学生分 小组, 分角色, 自编自导, 然后, 根据场景设计和理论知 识进行讨论。又如, 在讲授《战略管理》时, 模仿战略规 划决策的场景, 让组织学生参与到决策中。而后, 再结合 学生的场景模拟, 讲授具体的相关理论。这样, 学生可以
获得更直观更具体的感受, 对课程内容的印象也会更加深 刻。

\section{3 案例教学法重在激发学生的兴趣和主动性}

国内许多高校工商管理专业对于案例教学已经非常重 视, 大多开设了案例课程, 或者要求教师在授课过程中注 重案例的穿插。但实际上, 很多案例教学并没有达到预期 的效果。其主要原因在于国内灌输式教学模式根深蒂固, 教师过于包办, 从收集案例, 题目设计, 问题回答等等环 节, 学生参与较少。国外教师常常组织学生案例, 自己组 织讨论, 自己发现问题, 并找到解决问题的办法, 并在课 下总结形成报告, 课堂上通过小组展示进行评比, 教师点 评。例如, 老师布置学生自行采访企业高管或企业家, 了 解企业战略或创业经历等等, 学生总结采访记录, 撰写采 访心得。实践证明, 学生动手参与设计越多, 学生的积极 性越高, 更有助于能力的锻炼和提高。

\section{4 实习基地教学给学生实战演练的机会}

实习的过程所获得的知识很可能是课本上不会介绍, 课堂上也学不到的实践经验。国外高校通常给工商管理专 业的学生提供多家公司作为实习基地, 每一个学生都可以 在实习基地的公司实习, 从而学习与专业相关的实践知识。 另外, 学校鼓励学生利用业余时间或假期在公司做兼职, 实习的学分必须达到总学分的一定比例才能毕业。而且, 教师会定期聘期企业管理人员来课堂客串。以《创业管理》 为例, 课程的主要内容包括市场策划、企业融资、创业企 业上市等等。教师会在讲述每一部分时, 都聘期一位企业 创始人来到课堂, 结合自己的创业经历给学生讲解核心知 识点。并且, 教师请来的企业创始人恰恰就是本校以往的 毕业生。这也在很大程度上激发了学生的创业热情和信心。 同时, 国外高校在制度上比较宽松, 支持学生选修晚上或 寒暑假的课程, 集中学习, 提前修满学分, 提前毕业。通 常, 大部分学生可以提前 1 年或半年毕业。同时, 教师集 中 1-2 个月把原本 1 个学期的课程讲完, 这样, 余下大量 时间就可以用于科研和参加学术研讨。

\section{参考文献(References)}

[1] Jiang Guihuang and Zhang Xinrui, "Comparative study on industrial and commercial management of university curriculum system in China”, University Education, 2014(7).

[2] Du Caiping, Xing Xiaohong, Chen Changxing. "Innovation of application-oriented talents cultivation in local colleges construct the curriculum system", Modern Education Science, 2012(21) 